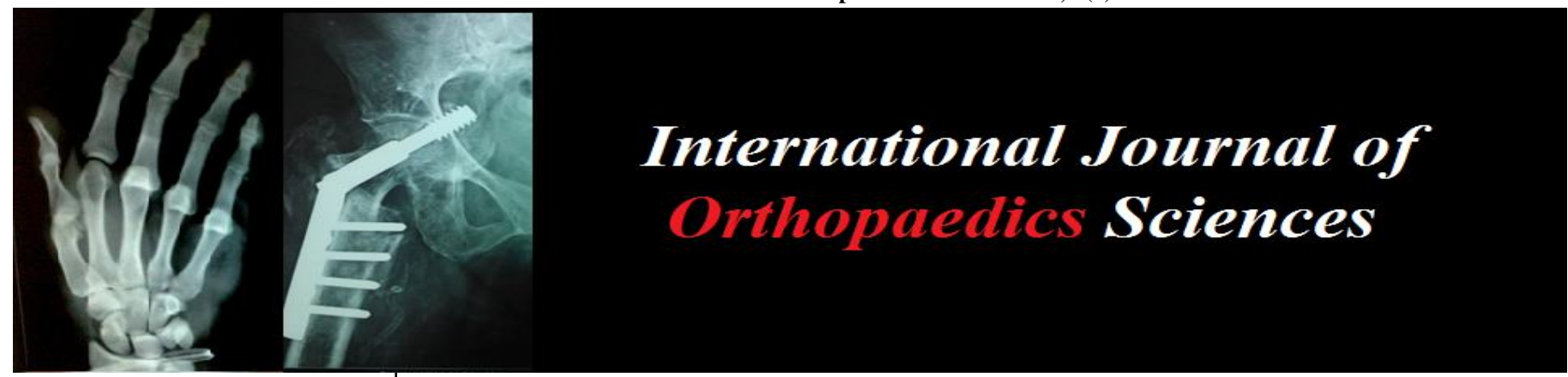

ISSN: $2395-1958$

IJOS 2018; 4(3): 526-529

(C) 2018 IJOS

www.orthopaper.com

Received: 03-05-2018

Accepted: 04-06-2018

Dr. Shashi Kant Kumar Singh Senior Resident, Department of Orthopaedics, RIMS, Ranchi

Jharkhand, India

Dr. Ankur Ojha

$3^{\text {rd } y r . ~ J u n i o r ~ R e s i d e n t ~ A c a d e m i c ~}$

Department of Orthopaedics, RIMS, Ranchi, Jharkhand,

India

Dr. LB Manjhi

Prof, Head of Department Department of Orthopaedics, RIMS, Ranchi, Jharkhand, India

\section{Functional outcome of Philos plate fixation in proximal humerus fractures}

\author{
Dr. Shashi Kant Kumar Singh, Dr. Ankur Ojha and Dr. LB Manjhi
}

DOI: https://doi.org/10.22271/ortho.2018.v4.i3j.93

\section{Abstract}

Background: Conservative treatment for Proximal humeral fractures were common in the past and often had compromised functional results. With the advancement of surgical techniques, proximal humerus fractures are now more often managed operatively for early rehabilitation and better functional outcome. The aim of this study was to assess the functional outcome of PHILOS plate fixation in proximal humerus fractures.

Materials and Methods: A prospective, non-controlled, non-randomized study was conducted on patient admitted in our institution between July 2016 and August 2017 with displaced proximal humeral fractures with mean age of 50 years (range 24-75years). 15 patients were selected for the study. The outcome was assessed based on Constant-Murley score.

Results: Results were analysed according to Constant-Murley score. Excellent results were achieved in 3 (20\%), good results in 7 (46.66\%), fair results in $3(20 \%)$ and poor result in $2(13.33 \%)$ of the cases. Avascular necrosis (AVN) and non-union was observed in one patient.

Conclusion: PHILOS plate fixation for proximal humeral fracture is a good stable fixation with a good functional outcome especially in osteopenic elderly patients

Keywords: Philos plating, proximal humerus fractures

\section{Introduction}

Proximal humeral fractures account for approximately $5 \%$ of all fractures. It is more common in old age females. Proximal humeral fractures are the second most common upper-extremity fracture and the third most common fracture, in old age patients who are more than sixty-five years of age. They are about $5 \%$ of all injuries to appendicular skeleton ${ }^{[1]}$. In younger individuals, the cause of these fractures are basically high velocity trauma, whereas a simple fall may lead to fracture in older individuals because of osteopenia and osteoporosis. A major proportion of these fractures are stable, nondisplaced or minimally displaced and can be treated conservatively ${ }^{[2]} .80-85 \%$ of undisplaced or minimally displaced fractures are treated conservatively. In approximately $20 \%$ of displaced fractures operative treatment may be beneficial ${ }^{[3]}$. The indication for fixing such a fracture depends on the fracture pattern, quality of bone and the age and activity of the patient. Many surgical techniques have evolved for treatment of displaced or comminuted proximal humerus fractures. Percutaneous pinning and intramedullary nailing have satisfactory results and have a a low risk for infection, soft tissue disruption, and blood loss ${ }^{[6]}$ However, many of these constructs are less stable than open reduction and internal fixation (ORIF) with locking plates ${ }^{[5,6]}$

Open reduction and internal fixation (ORIF) with locking plating is a promising option in the treatment of displaced, comminuted proximal humerus fractures. The benefits includes improved fracture stability because of the fixed-angle construct, especially in more comminuted fracture patterns and in osteopenic bone; a short period of immobilization with earlier rehabilitation ${ }^{[9]}$ This study is conducted to report the outcome following this technique as a surgical option.

\section{Materials and Methods}

A prospective, non-controlled, non-randomized study was conducted on patient admitted in Department of Orthopaedics, RIMS, Ranchi between July 2016 and August 2017
Dr. Shashi Kant Kumar Singh Senior Resident, Department of Orthopaedics, RIMS, Ranchi Jharkhand, India 
(one year duration) with displaced proximal humeral fractures with mean age of 50 years (range 24-75years). 15 patients were selected for the study.

\section{Inclusion criteria}

1. Closed proximal humeral fracture

2. Failed non-operative treatment

3. Age older than $20 \mathrm{yrs}$

\section{Exclusion criteria}

1. Open fractures

2. Pathological fractures

Radiographs of shoulder anteroposterior view and axillary view were taken and fractures were classified according to the Neers classification. Patients underwent open reduction and internal fixation with PHILOS for the sustained fractures under anaesthesia.

\begin{tabular}{|c|c|c|c|}
\hline & 2 part & 3 part & 4 part \\
\hline $\begin{array}{l}\text { Anatomical } \\
\text { neck }\end{array}$ & & & \\
\hline Surgical ne & & & \\
\hline $\begin{array}{l}\text { Greater } \\
\text { tuberosity }\end{array}$ & & & \\
\hline $\begin{array}{l}\text { Lesser } \\
\text { tuberosity }\end{array}$ & & & \\
\hline $\begin{array}{l}\text { Fracture } \\
\text { dislocation } \\
\text { anterior }\end{array}$ & & & \\
\hline $\begin{array}{l}\text { Fracture } \\
\text { dislocation } \\
\text { posterior }\end{array}$ & & & \\
\hline
\end{tabular}

Fig 1: Neer's Classification

\section{Surgical Technique}

The standard deltopectoral approach was used in all cases with patient in beach chair position. For fracture reduction temporary fixation with $\mathrm{K}$ - wires was done. The plate was positioned distal to the tip of the greater tuberosity. The distal humeral screws were having bicortical purchase. Proximal locking screws were extended till subchondral area. After confirmation of adequate fixation under image intensifier, the wound was closed in layers with proper anti septic dressing. Immediate post-operative radiographs were taken to assess the alignment of bone and maintenance of reduction. Patients were followed up at 1st post-operative day, 6weeks, 3 months and 6 months after the surgery.

Our physiotherapy regime consisted of polysling for 3 weeks with pendulum exercises started from $3^{\text {rd }}$ post-operative day, followed by active assisted external rotation to neutral and active assisted flexion. At 6 weeks they were allowed full range of movements. Resistive strengthening was begun after fracture union had been ensured.

The final results were evaluated using the Constant-Murley score: This system base on 100 point score composed of a number of individual parameters. The subjective parameters assess the degree of pain the patient experiences and the ability to perform normal tasks of daily living. Both of these assessments are subjective and are carried out independently prior to objective testing of active motion range and shoulder power. Constant score were categorized as <30 =unsatisfactory; 30-39=fair; 40-59=good; 60-69=very good; and 70 and over $=$ excellent $^{[20]}$

\section{Results}

This study consisted of total 15 patients. In the present study maximum numbers of patients were found to be in fifth and sixth decades with average age 50 years (range 24-75years). There were 9 male and 6 female patients with Male: Female sex ratio of 3:2. Left side $9(60 \%)$ proximal humeral fractures were more than right side $6(40 \%)$ in the present study. Mode of injury was Fall on outstretched hand from standing position(low energy trauma) in $5(33.33 \%)$, Motor vehicle accidents in $6(40 \%)$, Fall from height in $3(20 \%)$ and assault in $1(6.66 \%)$ patient. As per Neer's type; 8 were 2 part $(53.33 \%), 5$ were 3 part $(33.33 \%)$ while 2 were 4 part $(13.33 \%)$ fractures. Fracture union was achieved in all the patients with a mean duration of 12 weeks. All the cases were followed up as per protocol and findings were recorded. Results were analysed according to Constant-Murley score. Excellent results were achieved in $3(20 \%)$, good results in 7 $(46.66 \%)$, fair results in $3(20 \%)$ and poor result in 2 $(13.33 \%)$ of the cases. Total mean constant score was 72.2. The mean constant score in cases above $60 \mathrm{yrs}$ of age is 56.5 and the mean constant score in patients below $60 \mathrm{yr}$ of age is 82.7. No intra-operative complication was seen in any of the cases. Two patients developed subacromial impingement due superior positioning of plate and one patient had nonunion and avascular necrosis. 
Table 1: Age distribution

\begin{tabular}{|c|c|c|}
\hline Age distribution & Male & Female \\
\hline $20-40$ & 4 & 0 \\
\hline $40-60$ & 3 & 2 \\
\hline$>60$ & 2 & 4 \\
\hline
\end{tabular}

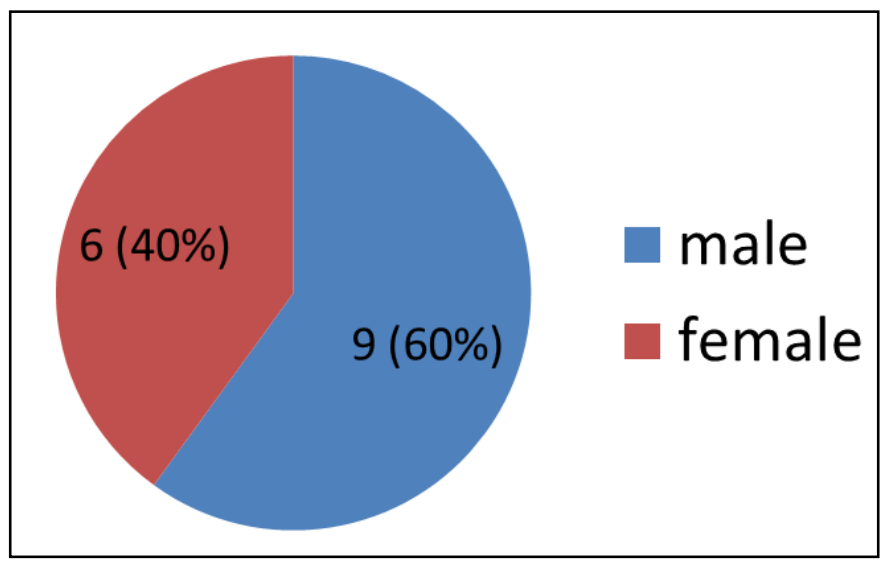

Fig 2: Gender Distribution

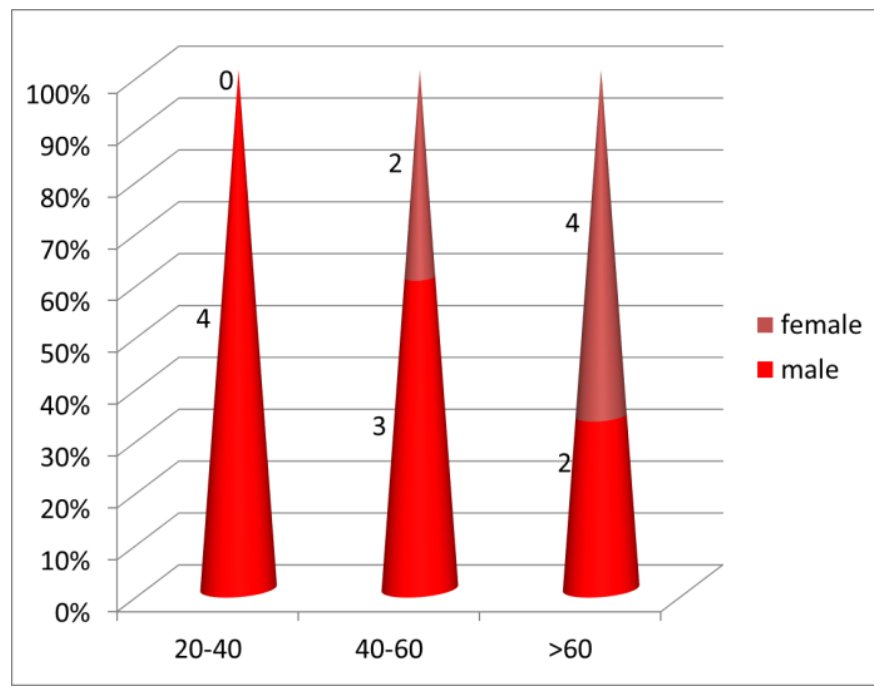

Fig 3: Gender distribution according to age group

Table 2: Functional outcome

\begin{tabular}{|c|c|c|}
\hline Constant Murley score & Outcome & No of patients \\
\hline $86-100$ & excellent & 3 \\
\hline $71-85$ & good & 7 \\
\hline $56-70$ & moderate & 3 \\
\hline$<55$ & poor & 2 \\
\hline
\end{tabular}

\section{Discussion}

Surgical fixation of the proximal humeral fractures is a challenging task for orthopaedic surgeons and has been controversial. A major proportion of these fractures are stable, nondisplaced or minimally displaced and can be treated conservatively ${ }^{[2]}$. For displaced proximal humerus fractures, treatment with conventional plates and screws have been reported with high rates of unsatisfactory outcomes and complications ${ }^{[10]}$ Locking plates are angular stable plates which has advantage of secure fixation in metaphyseal and osteoporotic bones. Locking plates are proven with biomechanical studies that they resist physiological loads more effectively ${ }^{[11,12]}$ There are many clinical studies which indicate that proximal humerus locking plates have good result in proximal humerus fractures ${ }^{[13-15]}$. Functional outcome not only depends on the quality of bone stock, but also on the stability provided by the implant. In an internal locking system like the PHILOS plate, all forces are transmitted from the bone via the locking head screws to the blade, and vice versa. Hence, the principle of fixed angle plates enables a gain in torsional stiffness and stability, and may therefore promote a superior outcome.

The average incidence of age in our series of 15 patients sutdy, was 50 years, which was consistent with the age of incidence in studies done by Egol et al, (61 years) and the average age of incidence in Gerber et al, study was 44.9 years $[18,19]$. Further as compared with other studies, our study showed a higher incidence of proximal humerus fractures in men than in women. The gender ration was $3: 2$, this can be explained by a higher day to day activities in males as compared to females. In our study, fracture occurred on right side in 6 patients and on left side in 9 patients. Gerber reported, in their series of 34 fractures, 16 were on left side and 18 were on right side ${ }^{[19]}$ The most common fracture pattern in our study was two - part fracture. Similar observations had also been reported by Björkenheim et al. ${ }^{[8]}$ By contrast, Koukakis et al, Rose et al, Siwach et al, and Fankhauser et al had reported a significant higher incidence of three-part fractures in their series [13, 14, 21, 22]

Thyagarajan et al in their study on 30 patients reported an average Constant score of 57.5 , with mean age of 58 years (range 19-92 years) and fractures were Neer's 2-part, 3-part, and 4-part fractures ${ }^{[16]}$. Aggarwal et al found moderate to excellent outcome in $90 \%$ of patients in their study. Constant score for younger patients was also significantly higher $(\mathrm{p}=0.12)$. The mean age of the patients was reported as 58.51 years (range 23-81 years) and fracture types were Neer 2-part, 3-part, and 4-part fractures and fracture dislocations ${ }^{[17]}$. In our study mean constant score was 72.2 which is comparable with other studies mentioned.

AVN of the humeral head is a known complication of proximal humeral fracture, reported most commonly with four-part fractures. Kilic et al used Philos for fixation of proximal humeral fractures and reported AVN in only one of 22 patients in their series ${ }^{[23]}$ Korkmaz et al did not observe osteonecrosis in any of their 41 patients operated using the same implant. ${ }^{24}$ Frangen et al reported osteonecrosis in 11 patients ( 6 were partial and 5 total) ${ }^{[7]}$. In our study, there was avascular necrosis (AVN) of the humeral head in only one patient.

\section{Conclusion}

The study has presented a surgical option in the management of displaced proximal humeral fractures Adequate surgical skills and surgeon's experiences with the surgical technique are necessary to achieve correct implant fixation and avoid intraoperative errors. Also postoperative physiotherapy plays an important role in rehabilitation of the patient to provide good results. This study shows it gives good functional outcome in young patients. The elderly were able to return to independent active living and the PHILOS plate can give good results in the treatment of displaced proximal humeral fractures. There are two limitations to our study, first number of cases are small, secondly few patients were elderly. The benefits of this implant were enhanced purchase in osteopaenic bone, No loss of reduction or valgus/varus angulations and Provide angular and axial stability of the construct. Our study concludes that PHILOS plate is suitable for proximal humeral fractures especially in osteopenic elderly patients. 


\section{References}

1. Court Brown CM, Caesar B. Epidemiology of adult fractures: A review Injury. 2006; 37:691-7.

2. Young TB, Wallace WA. Conservative treatment of fractures and fracture-dislocations of the upper end of the humerus J J Bone Joint Surg Br. 1985; 67(3):373-7.

3. Rose SH, Melton LJ 3rd, Morrey BF, Ilstrup DM, Riggs BL. Epidemiological features of humeral fractures Clin Orthop. 1982; 168:24-30.

4. Sahu RL. Philos Locking plates in proximal humerus fractures literature review. Internet J Health. 2010; 11:1.

5. Aaron D, Shatsky J, Paredes JC. Proximal humeral fractures: internal fixation. J Bone Joint Surg Am. 2012; 94(24):2280-8.

6. Murray IR, Amin AK, White TO, Robinson CM. Proximal humeral fractures: current concepts in classification, treatment and outcomes. J Bone Joint Surg Br. 2011; 93(1):1-11.

7. Frangen TM, Müller EJ, Dudda M, Arens S, Muhr G, K€alicke T. Proximal humeral fractures in geriatric patients. Is the angle-stable plate osteosynthesis really a breakthrough? Acta Orthop Belg. 2007; 73:571-9.

8. Björkenheim JM, Pajarinen J, Savolainen V. Internal fixation of proximal humeral fractures with locking compression plate: A retrospective evaluation of 72 patients followed for a minimum of 1 year. Acta Orthop Scand. 2004; 75:741-5.

9. Flores S, Merk BR. Two-part surgical neck fractures of the proximal part of the humerus: A biomechanical evaluation of two fixation techniques. J Bone Joint Surg Am. 2006; 88:2258-64.

10. Kristiansen B, Christensen SW. Plate fixation of proximal humeral fractures. Acta Orthop Scand. 1986; 57:320-3.

11. Lever JP, Aksenov SA, Zdero R, Ahn H, McKee MD, Schemitsch EH. Biomechanical analysis of plate osteosynthesis systems for proximal humerus fractures. J Orthop Trauma. 2008; 22:23 9.

12. Seide K, Triebe J, Faschingbauer M, Schulz AP, Püschel $\mathrm{K}$, Mehrtens $\mathrm{G}$ et al. Locked vs. unlocked plate osteosynthesis of the proximal humerus A biomechanical study. Clin Biomech (Bristol, Avon). 2007; 22:176-82.

13. Koukakis A, Apostolou CD, Taneja T, Korres DS, Amini A. Fixation of proximal humerus fractures using the PHILOS plate: Early experience. Clin Orthop Relat Res. 2006; 442:115-20.

14. Fankhauser F, Boldin C, Schippinger G, Haunschmid C, Szyszkowitz R. A new locking plate for unstable fractures of the proximal humerus. Clin Orthop Relat Res. 2005; 430:176-81.

15. Moonot P, Ashwood N, Hamlet M. Early results for treatment of three and four part fractures of the proximal humerus using the PHILOS plate system. J Bone Joint Surg Br. 2007; 89:1206-9.

16. Thyagarajan DS, Haridas SJ, Jones D, Dent C, Evans R, Williams R. Functional outcome following proximal humeral interlocking system plating for displaced proximal humeral fractures. Int J Shoulder Surg. 2009; 3:57-62.

17. Aggarwal S, Bali K, Dhillon MS, Kumar V, Mootha AK. Displaced proximal humeral fractures: An Indian experience with locking plates. J Orthop Surg Res. 2010; 5:60.

18. Egol KA, Ong CC, Walsh M, Jazrawi LM, Tejwani NC, Zuckerman JD. Early complication of proximal humerus fractures treated with locked plates. J Ortho Trauma. 2008; 22:159-64.

19. Gerber C, Worner CM, Vienne P. Internal fixation of complex fractures of the proximal humerus. J Bone Joint Surg (Br). 2004; 86(60):848-55.

20. Booker S, Alfahad N, Scott M, Gooding B, Wallace WA. Use of scoring systems for assessing and reporting the outcome results from shoulder surgery and arthroplasty. World J Orthop. 2015; 6(2):244-51.

21. Rose PS, Adams CR, Torchia ME, Jacofsky DJ, Haidukewych GG, Steinmann SP. Locking plate fixation for proximal humeral fractures: initial results with a new implant. J Shoulder Elbow Surg. 2007; 16(2):202-7.

22. Siwach R, Singh R, Rohilla RK, Kadian VS, Sangwan SS, Dhanda M. Internal fixation of proximal humeral fractures with locking proximal humeral plate (LPHP) in elderly patients with osteoporosis. J Orthop Traumatol. 2008; 9(3):149-53.

23. Kilic B, Uysal M, Cinar BM, Ozkoç G, Demirörs H, Akpinar S. Early results of treatment of proximal humerus fractures with the PHILOS locking plate. Acta Orthop Traumatol Turc. 2008; 42(3):149-53.

24. Korkmaz MF, Aksu N, Gogus A, Debre M, Kara AN, Işiklar ZU. The results of internal fixation of proximal humeral fractures with the PHILOS locking plate. Acta Orthop Traumatol Turc. 2008; 42(2):97-105. 